\title{
Investigations of alkynylbenziodoxole derivatives for radical alkynylations in photoredox catalysis
}

\author{
Yue Pan ${ }^{1,2}$, Kunfang $\mathrm{Jia}^{2}$, Yali Chen ${ }^{* 1}$ and Yiyun Chen ${ }^{* 1,2}$
}

\section{Full Research Paper}

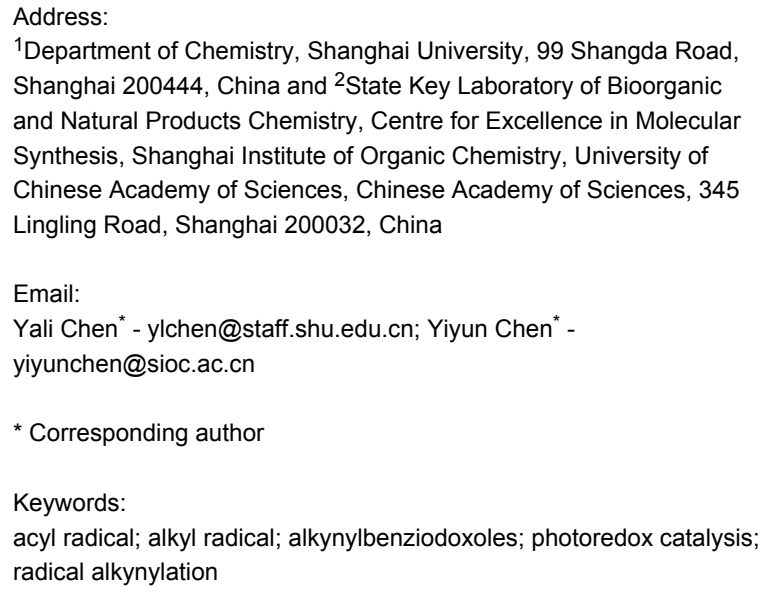

${ }^{1}$ Department of Chemistry, Shanghai University, 99 Shangda Road, Shanghai 200444, China and ${ }^{2}$ State Key Laboratory of Bioorganic and Natural Products Chemistry, Centre for Excellence in Molecular Synthesis, Shanghai Institute of Organic Chemistry, University of Chinese Academy of Sciences, Chinese Academy of Sciences, 345 Lingling Road, Shanghai 200032, China

Email:

Yali Chen* - ylchen@staff.shu.edu.cn; Yiyun Chen* -

yiyunchen@sioc.ac.cn

* Corresponding author

Keywords:

acyl radical; alkyl radical; alkynylbenziodoxoles; photoredox catalysis; radical alkynylation

Beilstein J. Org. Chem. 2018, 14, 1215-1221.

doi:10.3762/bjoc. 14.103

Received: 12 February 2018

Accepted: 04 May 2018

Published: 28 May 2018

This article is part of the Thematic Series "Hypervalent iodine chemistry in organic synthesis".

Guest Editor: T. Wirth

(C) 2018 Pan et al.; licensee Beilstein-Institut.

License and terms: see end of document.

\begin{abstract}
The alkynylbenziodoxole derivatives are recently developed alkynylation reagents in organic synthesis, which demonstrate excellent radical alkynylation reactivity in photoredox catalysis reactions. Herein we report the synthesis of alkynylbenziodoxole derivatives with difluoro, monofluoro, monomethoxy, and dimethoxy substitution on the benziodoxole moiety, and investigated their radical alkynylation reactivity for the first time. A series of mechanistic experiments were conducted to study the radical acceptor and oxidative quencher reactivity of alkynylbenziodoxoles, in which unsubstituted alkynylbenziodoxoles played balancing roles in both processes, while electron-rich benziodoxole derivatives demonstrate synthetic advantages in some cases.
\end{abstract}

\section{Introduction}

The introduction of the alkynyl group to organic molecules is an important synthetic transformation in organic synthesis [1-4]. Recently, cyclic iodine(III) reagents (CIR)-substituted alkynes, alkynylbenziodoxoles, were developed with readily preparation and shelf-stableness [5-10]. The alkynylbenziodoxoles were first synthesized by the Ochiai group, and later studied by Waser and other groups for the use in electrophilic alkynylation reactions [11-18]. In 2012, the Li group first used alkynylbenziodoxoles for decarboxylative radical alkynylation under silver salt and persulfate conditions [19]. In 2014, the Chen group discovered that alkynylbenziodoxoles (BI-alkyne) readily participated in photoredox catalysis as the radical alkynylation reagent [20], after which various applications in photoredox catalysis were reported [21-27]. 
Currently, the use of BI-alkyne for radical alkynylation is limited to unsubstituted alkynylbenziodoxoles. While effective, its reactivity with some radical precursors was compromised [19-27]. The Waser group pioneered the study of substituted alkynylbenziodoxoles for the electrophilic alkynylation reactivity, however, no significant improvements were observed by the derivatizations [28-32]. Herein, we report the synthesis of alkynylbenziodoxole derivatives and investigate their reactivity toward alkyl radical and acyl radical additions in photoredox catalysis. The mechanistic investigations were carried out to study the derivatization of BI-alkynes in radical acceptor and oxidative quencher reactivity, and the electron-rich benziodoxole derivatives demonstrated synthetic advantages in some cases (Scheme 1).

\section{Results and Discussion}

We started the synthesis of BI-alkyne derivatives with substituted $o$-iodobenzoic acids 1 bearing 3,4-difluoro, 4-fluoro, 3-methoxy, 4-methoxy, or 3,4-dimethoxy substitutions (Scheme 2). Using a slightly modified Ochiai procedure [11], the substituted hydroxybenziodoxoles $\mathbf{2 a}-\mathbf{f}$ were prepared with periodate oxidation in $75-90 \%$ yield, in which the electronic effect did not have much influence on the reaction [33]. Subsequently, the treatment with trimethylsilyl $p$-tolylacetylene in the presence of trimethylsilyl trifluoromethanesulfonate afforded $p$-tolylacetylenic benziodoxoles $\mathbf{3 a}-\mathbf{f}$ in $25-65 \%$ yield, in which the electron-donating substitutions were beneficial for the reaction. The two-step synthesis of BI'-alkyne derivatives $\mathbf{3 a}, \mathbf{b}, \mathbf{d}-\mathbf{f}$

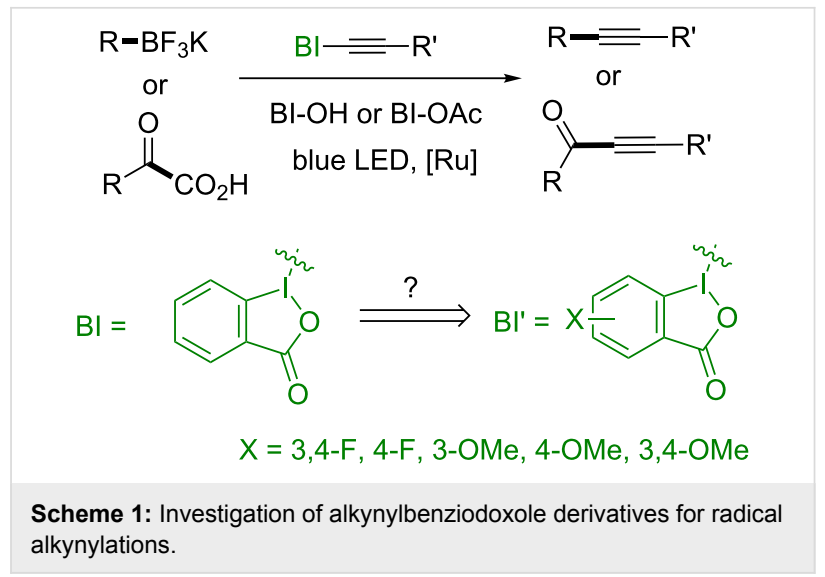

were in the range of $23-50 \%$ yield in gram scale, which was comparable to the synthesis of unsubstituted BI-alkyne 3c.

The ${ }^{13} \mathrm{C}$ NMR spectra of BI-alkynes $\mathbf{3 a}-\mathbf{f}$ were studied with the focus on the $\alpha$-carbon, which position directly underwent $\alpha$-radical addition [19]. The electron density of the $\alpha$-carbon was decreased in 3a with electron-deficient 3,4-difluoro groups on the benziodoxole, and was increased for $\mathbf{3 f}$ with electrondonating 3,4-dimethoxy groups. Cyclic voltammetry measurements were also carried out for BI-alkynes $\mathbf{3 a}-\mathbf{f}$, in which the reduction potential ( $E \mathrm{p}$ re) indicated the electron-accepting capacity of the BI-alkynes. As expected, the reduction potential of 3a was increased with electron-deficient 3,4-difluoro substituents on the benziodoxole, and was decreased for $\mathbf{3 f}$ with elec-
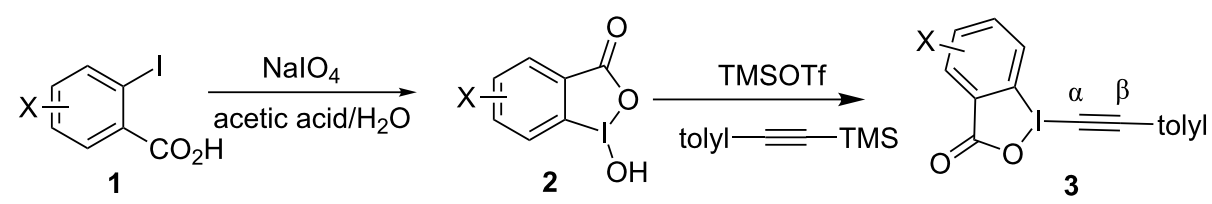

reaction 1<smiles>O=C1O[IH](=[IH])c2cc(F)c(F)cc21</smiles>

$X=3,4-F$

2a, $90 \%$ yield

$3 a, 25 \%$ yield<smiles>C[Al]1OC(=O)c2cc(F)ccc21</smiles>

$X=4-F$

2b, $90 \%$ yield

$3 \mathrm{~b}, 38 \%$ yield<smiles>O=C1O[Te]([Tl])c2ccccc21</smiles>

$\mathrm{X}=\mathrm{H}$

2c, $90 \%$ yield

$3 c$, $59 \%$ yield<smiles>COc1ccc2c(c1)I(C)OC2=O</smiles>

$\mathrm{X}=3-\mathrm{OMe}$

2d, $75 \%$ yield

3d, $48 \%$ yield<smiles>CCC[In]1OC(=O)c2cc(OC)ccc21</smiles>

$X=4-O M e$

2e, $78 \%$ yield

3 e, $61 \%$ yield

$\mathrm{X}=3,4-\mathrm{OMe}$

2f, $77 \%$ yield

3f, $65 \%$ yield

$\begin{array}{llc}{ }^{13} \mathrm{C} \alpha(\mathrm{ppm}) & 110.7 & 105.5 \\ { }^{13} \mathrm{C} \beta(\mathrm{ppm}) & 56.6 & 51.0 \\ \begin{array}{l}\text { Ep re }(\mathrm{V} \text { vs } \\ \text { SCE in MeCN) }\end{array} & 1.97 & 1.94 \\ \begin{array}{l}\text { Ep ox }(\mathrm{V} \text { vs } \\ \text { SCE in MeCN) }\end{array} & -0.95 & -1.06 \\ \end{array}$

107.2

105.2

105.0

104.9

49.3

52.9

56.4

52.5

1.87

1.91

1.87

1.78

$-1.20$

$-1.09$

$-1.20$

$-1.12$ 
tron-donating 3,4-dimethoxy groups. It is interesting to note that the effect of single substitution on benziodoxoles in $\mathbf{3 b}, \mathbf{3 d}$ and 3e was insignificant and sporadical in both ${ }^{13} \mathrm{C}$ NMR spectroscopy and cyclic voltammetry experiments.

We next tested the reactivity of tolylacetylenic benziodoxole derivatives 3a-f for deboronative alkynylation under photoredox catalysis conditions (Scheme 3) [20,34]. Using the tertiary alkyl trifluoroborate $\mathbf{4 a}$ as the alkyl radical precursor under literature conditions, the unsubstituted BI-alkyne $\mathbf{3 c}$ only results in $50 \%$ yield of alkynylation adduct $\mathbf{5 a}$, which is consistent with the literature report that tertiary alkyl trifluoroborates did not give satisfying results [20]. Using BI'-alkyne 3a with 3,4-difluoro substitutions, the alkynylation adduct 5a was obtained in decreased $47 \%$ yield. In contrast, $74 \%$ yield of $\mathbf{5 a}$ was obtained with 3,4-dimethoxy-substituted BI'-alkyne 3f. Being consistent with the ${ }^{13} \mathrm{C}$ NMR spectroscopy and cyclic voltammetry experiments, the effect of single substitution on the benziodoxole was insignificant and no improvement was observed.
We also tested the secondary alkyl trifluoroborate $\mathbf{4 b}$ and primary alkyl trifluoroborate $\mathbf{4 c}$, in which the deboronative alkynylation with unsubstituted BI-alkynes already gave good results. The electronic effects on the benziodoxoles were less significant and fluctuated within the 5\% yield range: The alkynylation adducts $\mathbf{5 b}$ and $\mathbf{5 c}$ were obtained in decreased $80 \%$ and $65 \%$ yields using BI'-alkyne $3 \mathrm{a}$, while $86 \%$ and $73 \%$ yields of $\mathbf{5 b}$ and $\mathbf{5 c}$ were obtained with BI'-alkyne 3f. We then tested benzyl trifluoroborate $\mathbf{4 d}$ and oxygen-substituted alkyl trifluoroborate $4 \mathbf{e}$, which were not reported for deboronative alkynylations before. The 3,4-dimethoxy-substituted BI'-alkyne 3 f gave the optimal $70 \%$ and $82 \%$ yields of alkynes $\mathbf{5 d}$ and $\mathbf{5 e}$, which observed $\approx 10 \%$ yield improvement comparing to the unsubstituted BI-alkyne 3c.

We then tested if the propensity of BI-alkyne derivatives toward alkyl radical additions was general and could extend to other alkyl radical precursors (Scheme 4). Tertiary alcohols 6 were reported to be activated by cyclic iodine(III) reagents under a)

$$
\mathrm{R}-\mathrm{BF}_{3} \mathrm{~K}+\mathrm{Bl}=\text { tolyl }
$$

4<smiles>C[Te]1(C)OC(=O)[Y]2=CC1C=C2</smiles><smiles>CC1(C#CC=O)CCCC(=O)C1</smiles>

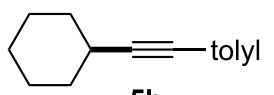

$5 b$<smiles>[Na]C([Na])([Mg])C#CCCc1ccccc1</smiles><smiles>O=C(O)C#CCc1ccccc1</smiles>

5d<smiles>O=[W]OCC#CCOCCc1ccccc1</smiles>

$47 \%$

3

$X=3,4-F$

$3 a$

$80 \%$

$83 \%$

N/P

$65 \%$

$62 \%$

$81 \%$

$3 \mathrm{~b}$

$39 \%$

N/P

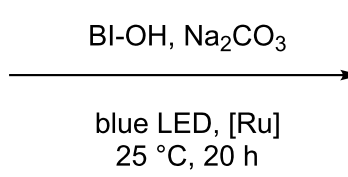

$X=4-F$

$50 \%$

$52 \%$

$47 \%$

$74 \%$

$X=$
$3 c$

$X=3-O M e$
$3 d$

$\mathrm{X}=4-\mathrm{OM}$

$3 e$

$X=3,4-O M e$

$3 f$

$83 \%$

$74 \%$

$84 \%$

$86 \%$

$68 \% \quad N / P$

N/P

$73 \%$

$60 \%$

N/P

N/P

$70 \%$

Scheme 3: Reaction of alkynylbenziodoxole derivatives for deboronative alkynylation in photoredox catalysis. Reaction conditions: a) alkyl potassium trifluoroborate 4 ( $0.15 \mathrm{mmol}, 1.5$ equiv), alkynylbenziodoxole $3\left(0.10 \mathrm{mmol}, 1.0\right.$ equiv), $\mathrm{Ru}(\mathrm{bpy})_{3}\left(\mathrm{PF}_{6}\right)_{2}(1.7 \mathrm{mg}, 0.002 \mathrm{mmol}, 0.02 \mathrm{equiv})$, hydroxybenziodoxole (BI-OH, 0.05 mmol, 0.5 equiv), and $\mathrm{Na}_{2} \mathrm{CO}_{3}\left(0.2 \mathrm{mmol}, 2.0\right.$ equiv) in $1.0 \mathrm{~mL} \mathrm{CH}_{2} \mathrm{Cl}_{2}$ and $1.0 \mathrm{~mL} \mathrm{H}_{2} \mathrm{O}$ for $20 \mathrm{~h}$ under a nitrogen atmosphere, unless otherwise noted; b) 4 ( $0.3 \mathrm{mmol}, 3.0$ equiv), $\mathrm{Na}_{2} \mathrm{CO}_{3}(0.4 \mathrm{mmol}, 4.0$ equiv). Yields are isolated yields. $\mathrm{N} / \mathrm{P}=\mathrm{not}$ performed. 
<smiles>[R]C([R])([R])O</smiles><smiles>[C+]1CCCCC1</smiles><smiles>[Mg]C#CC#C[BiH]</smiles>

3<smiles>[Y][AsH]=[AsH]</smiles>

$67 \%$

$6 a$<smiles>CC(C)(O)C1CCCCC1</smiles>

$75 \%$

$74 \%$ $\underset{\text { blue LED, [Ru] }}{\stackrel{\text { BI-OAc }}{\longrightarrow}}$

$25^{\circ} \mathrm{C}$<smiles></smiles>

7

$3 f$

$85 \%$

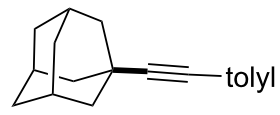

$7 a$

$80 \%$

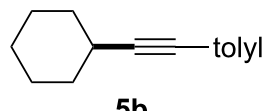

$5 b$

Scheme 4: Reaction of alkynylbenziodoxole derivatives for radical alkynylations in photoredox catalysis. Reaction conditions: tertiary alcohol 6 ( $0.25 \mathrm{mmol}, 2.5$ equiv), alkynylbenziodoxole $3\left(0.10 \mathrm{mmol}, 1.0\right.$ equiv), Ru(bpy) $3\left(\mathrm{PF}_{6}\right)_{2}(0.002 \mathrm{mmol}, 0.02$ equiv), and $\mathrm{BI}-\mathrm{OAc}(0.25 \mathrm{mmol}, 2.5$ equiv) in $2.0 \mathrm{~mL} \mathrm{DCE}$ for $24 \mathrm{~h}$ under a nitrogen atmosphere, unless otherwise noted. Yields are isolated yields.

photoredox conditions to generate alkoxyl radicals, and subsequently underwent $\beta$-fragmentation and alkynylation to yield 7 after eliminating the arylketone [25]. With tertiary alcohol 6a as the alkyl radical precursor, the unsubstituted BI-alkyne $\mathbf{3 c}$ gave $74 \%$ yield of $7 \mathbf{a}$, which was consistent with the literature report [25]. Under otherwise identical reaction conditions, 67\% yield of 7a was obtained with 3,4-difluoro BI'-alkyne 3a, while optimal $85 \%$ yield of $7 \mathbf{a}$ was obtained with 3,4-dimethoxy BI'alkyne 3f. We then tested the secondary alkyl radical precursor $\mathbf{6 b}$ and observed $74 \%$ yield of alkyne $\mathbf{5 b}$ using unsubstituted BI-alkyne 3c. In contrast, 3,4-dimethoxy BI'-alkyne 3f gave improved $80 \%$ yields of $\mathbf{5 b}$.
We finally moved to test the BI-alkyne derivatives toward acyl radical additions (Scheme 5). With ketoacid 8 as the acyl radical precursor, the decarboxylative alkynylation with BI-alkyne derivatives afforded ynone 9 under the photoredox conditions [21]. Both the unsubstituted and 3,4-dimethoxy substituted BI'-alkynes $\mathbf{3 c}$ and $\mathbf{3 f}$ gave ynone $\mathbf{9}$ in similar $77-79 \%$ yields, while the 3,4-difluoro substituted BI'-alkyne $\mathbf{3 a}$ gave a slightly lower $63 \%$ yield of 9 [21]. $\beta$-Ketone alcohols $\mathbf{1 0}$ were reported to be activated by cyclic iodine(III) reagents under photoredox conditions to generate alkoxyl radicals, and subsequently underwent $\beta$-fragmentation and alkynylation to yield ynone 9 [26]. The unsubstituted BI-alkyne 3c gave $84 \%$<smiles>O=C(O)C(=O)O[Na]</smiles>

$8^{\mathrm{a}}$<smiles>CC(C)(O)C(=O)O[Na]</smiles>
$10^{\mathrm{b}}$ $B$ 3

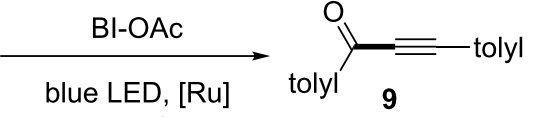

$25^{\circ} \mathrm{C}$

3a: $63 \%$; 3c: $77 \%$; 3 : $79 \%$

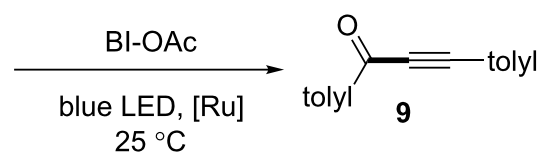

3a: $62 \%$; 3c: $84 \%$; 3f: $84 \%$

Scheme 5: Reaction of alkynylbenziodoxole derivatives for acyl radical alkynylation in photoredox catalysis. Reaction conditions: a) ketoacid 8 ( $0.15 \mathrm{mmol}, 1.5$ equiv), alkynylbenziodoxole $3\left(0.10 \mathrm{mmol}, 1.0\right.$ equiv), $\mathrm{Ru}(\mathrm{bpy})_{3}\left(\mathrm{PF}_{6}\right)_{2}(0.002 \mathrm{mmol}, 0.02$ equiv), and $\mathrm{BIOAc}(0.10 \mathrm{mmol}, 1.0$ equiv) in $2.0 \mathrm{~mL} \mathrm{DCM}$ for $5 \mathrm{~h}$ under a nitrogen atmosphere; b) $\beta$-ketone alcohol 10 ( $0.20 \mathrm{mmol}, 2.0$ equiv), alkynylbenziodoxole 3 ( $0.10 \mathrm{mmol}, 1.0$ equiv), $\mathrm{Ru}(\mathrm{bpy})_{3}\left(\mathrm{PF}_{6}\right)_{2}(0.002 \mathrm{mmol}, 0.02$ equiv), and $\mathrm{BI}-\mathrm{OAc}(0.20 \mathrm{mmol}, 2.0$ equiv) in $2.0 \mathrm{~mL} \mathrm{DCM}$ for $24 \mathrm{~h}$ under a nitrogen atmosphere. Yields are isolated yields. 
yield of 9 consistent with the literature report, while $62 \%$ yield of 9 was obtained with 3,4-difluoro BI'-alkyne 3a and 84\% yield of 9 was obtained with 3,4-dimethoxy BI'-alkyne $\mathbf{3 f}$.

With the preliminary hypothesis that the electron-withdrawing and electron-donating substituents on the benziodoxole have opposite effects for the radical alkynylation, we first conducted the fluorescence quenching experiments of tolylacetylenic benziodoxole derivatives $\mathbf{3 a}-\mathbf{f}$ and found none of them oxidatively quenched the photoexcited $\mathrm{Ru}(\mathrm{bpy}) 3_{3}{ }^{2+*}$ complex (see Supporting Information File 1, Scheme S1). We next investigated if the benziodoxole radical released from the radical alkynylation of BI-alkynes affected the reaction (Scheme 6). Using the combination of substituted hydroxybenziodoxoles (BI'-OH) and substituted BI'-alkynes, we found the 3,4-difluoro electronwithdrawing substituents either on BI'-OH or BI'-alkyne decreased the reaction yields, while the use of both further decreased the formation of $\mathbf{5 a}$ to $39 \%$ yield. In contrast, the use of electron-donating 3,4-dimethoxy group either BI'-OH or BI'alkyne increased the yields of $\mathbf{5 a}$ to $74 \%$ and $72 \%$ yields, while the use of both increased the formation of $\mathbf{5 a}$ to optimal $80 \%$ yield.

Based on mechanistic investigations above, we propose that the electronic effect on benziodoxoles affected both the radical acceptor and oxidative quencher reactivity of BI-alkyne derivatives (Scheme 7). In the alkyl or acyl radical addition step to BI'-alkyne (step 1) and the oxidative quenching step by benziodoxole radical (step 2), the electron-donating substituents on
BI'-alkynes are both beneficial, while the electron-withdrawing substituents have opposite effects.

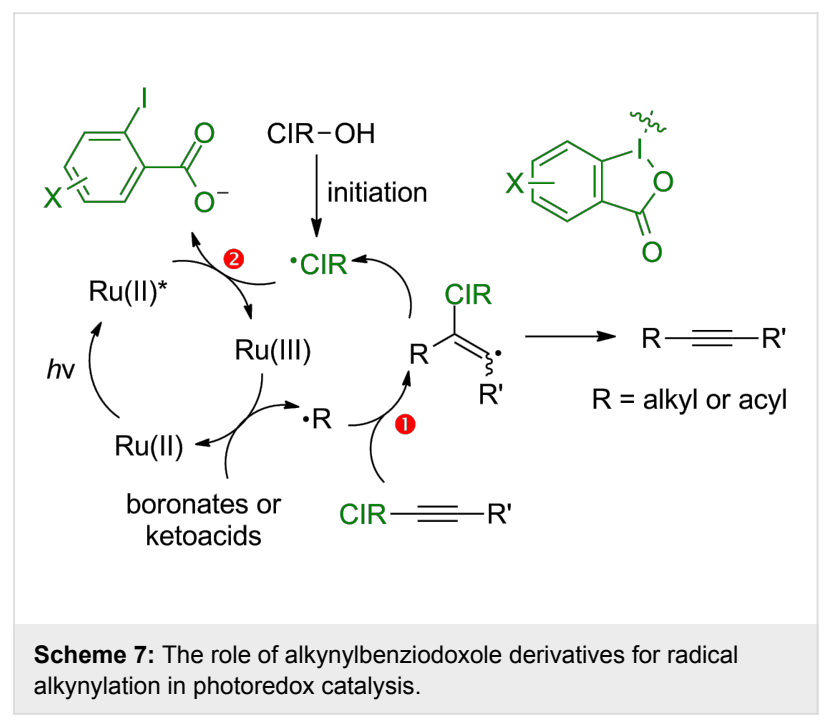

\section{Conclusion}

In conclusion, we have developed and investigated novel alkynylbenziodoxole derivatives as radical alkynylation reagents in photoredox catalysis reactions. Alkynylbenziodoxole derivatives with electron-rich benziodoxoles demonstrate synthetic advantages in some situations. The mechanistic investigations suggested both the radical acceptor (step 1) and oxidative quencher reactivity (step 2) were affected by BI-alkyne derivatization. We envision these alkynylbenz-

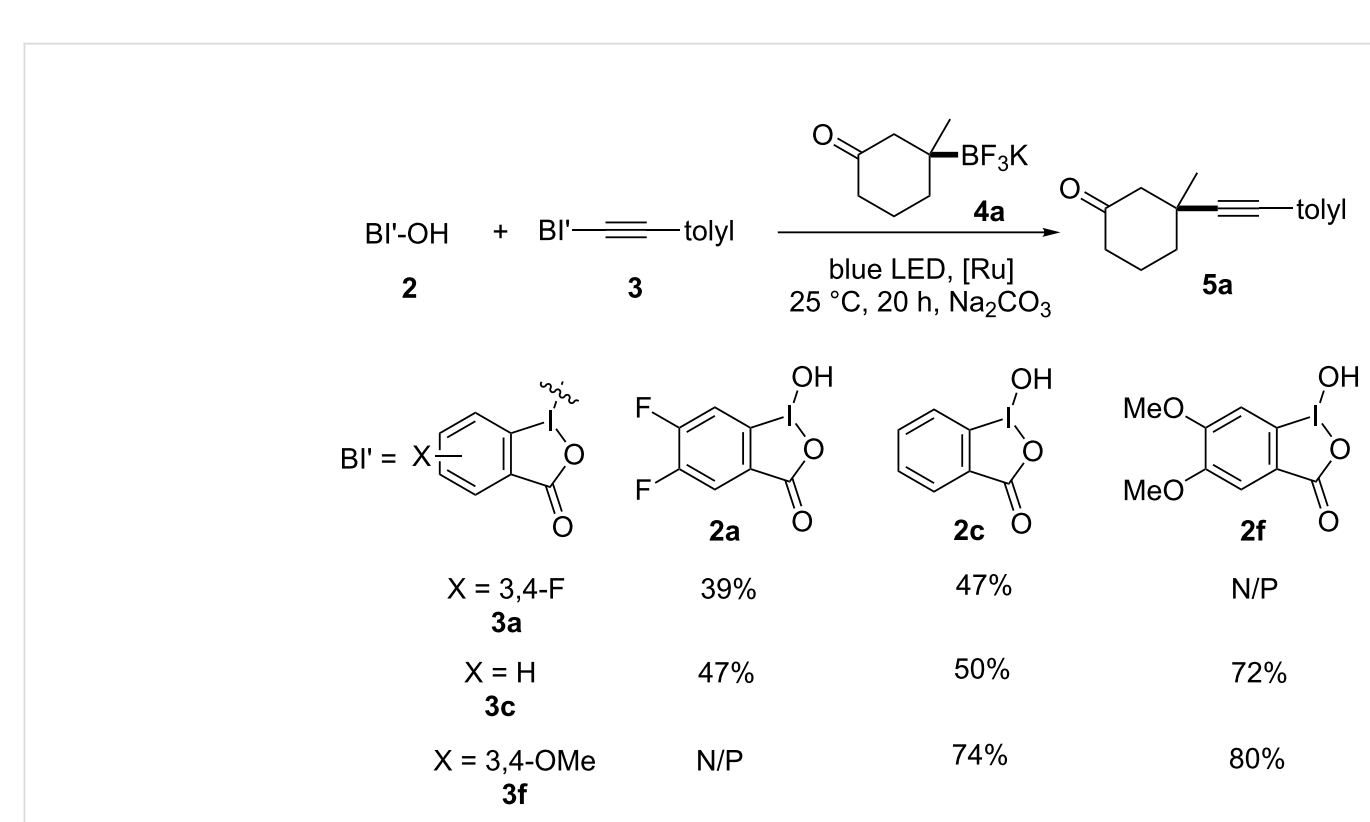

Scheme 6: Mechanistic investigations of alkynylbenziodoxole for radical acceptor and oxidative quenching reactivity. Yields are isolated yields. N/P = not performed. 
iodoxole derivatives will provide alternative radical alkynylation reagents in photoredox catalysis and other synthetic applications.

\section{Supporting Information}

\section{Supporting Information File 1}

Experimental details, and copies of ${ }^{1} \mathrm{H}$ NMR and ${ }^{13} \mathrm{C}$ NMR spectra for all new compounds.

[https://www.beilstein-journals.org/bjoc/content/ supplementary/1860-5397-14-103-S1.pdf]

\section{Acknowledgements}

Financial support was provided by National Natural Science Foundation of China 21472230, 21622207, 91753126, National Basic Research Program of China 2014CB910304, and Strategic Priority Research Program of the Chinese Academy of Sciences XDB20020200.

\section{ORCID ${ }^{\circledR}$ iDs}

Yiyun Chen - https://orcid.org/0000-0003-0916-0994

\section{References}

1. Jones, R. G.; Gilman, H. Chem. Rev. 1954, 54, 835-890. doi:10.1021/cr60171a004

2. Orita, A.; Otera, J. Chem. Rev. 2006, 106, 5387-5412. doi:10.1021/cr050560m

3. Chinchilla, R.; Nájera, C. Chem. Rev. 2007, 107, 874-922. doi:10.1021/cr050992x

4. Chinchilla, R.; Nájera, C. Chem. Soc. Rev. 2011, 40, 5084-5121. doi:10.1039/c1cs15071e

5. Stang, P. J.; Zhdankin, V. V. Chem. Rev. 1996, 96, 1123-1178. doi:10.1021/cr940424+

6. Zhdankin, V. V.; Stang, P. J. Chem. Rev. 2008, 108, 5299-5358. doi:10.1021/cr800332c

7. Yoshimura, A.; Zhdankin, V. V. Chem. Rev. 2016, 116, 3328-3435 doi:10.1021/acs.chemrev.5b00547

8. Zhdankin, V. V.; Stang, P. J. Tetrahedron 1998, 54, 10927-10966. doi:10.1016/S0040-4020(98)00410-4

9. Brand, J. P.; Waser, J. Chem. Soc. Rev. 2012, 41, 4165-4179. doi:10.1039/c2cs35034c

10. Li, Y.; Hari, D. P.; Vita, M. V.; Waser, J. Angew. Chem., Int. Ed. 2016, 55, 4436-4454. doi:10.1002/anie.201509073

11. Ochiai, M.; Masaki, Y.; Shiro, M. J. Org. Chem. 1991, 56, 5511-5513. doi:10.1021/jo00019a007

12. Zhdankin, V. V.; Kuehl, C. J.; Krasutsky, A. P.; Bolz, J. T.; Simonsen, A. J. J. Org. Chem. 1996, 61, 6547-6551. doi:10.1021/jo960927a

13. Brand, J. P.; Charpentier, J.; Waser, J. Angew. Chem., Int. Ed. 2009, 48, 9346-9349. doi:10.1002/anie.200905419

14. Collins, K. D.; Lied, F.; Glorius, F. Chem. Commun. 2014, 50, 4459-4461. doi:10.1039/c4cc01141d

15. Feng, C.; Loh, T.-P. Angew. Chem., Int. Ed. 2014, 53, 2722-2726. doi:10.1002/anie.201309198
16. Wang, Z. F.; Li, L.; Huang, Y. J. Am. Chem. Soc. 2014, 136, 12233-12236. doi:10.1021/ja506352b

17. Xie, F.; Qi, Z.; Yu, S.; Li, X. J. Am. Chem. Soc. 2014, 136, 4780-4787. doi:10.1021/ja501910e

18. Abegg, D.; Frei, R.; Cerato, L.; Prasad Hari, D.; Wang, C.; Waser, J.; Adibekian, A. Angew. Chem., Int. Ed. 2015, 54, 10852-10857. doi:10.1002/anie.201505641

19. Liu, X.; Wang, Z.; Cheng, X.; Li, C. J. Am. Chem. Soc. 2012, 134, 14330-14333. doi:10.1021/ja306638s

20. Huang, H.; Zhang, G.; Gong, L.; Zhang, S.; Chen, Y. J. Am. Chem. Soc. 2014, 136, 2280-2283. doi:10.1021/ja413208y

21. Huang, H.; Zhang, G.; Chen, Y. Angew. Chem., Int. Ed. 2015, 54, 7872-7876. doi:10.1002/anie.201502369

22. Tan, H.; Li, H.; Ji, W.; Wang, L. Angew. Chem., Int. Ed. 2015, 54 , 8374-8377. doi:10.1002/anie.201503479

23. Le Vaillant, F.; Courant, T.; Waser, J. Angew. Chem., Int. Ed. 2015, 54, 11200-11204. doi:10.1002/anie.201505111

24. Zhou, Q.-Q.; Guo, W.; Ding, W.; Wu, X.; Chen, X.; Lu, L.-Q.; Xiao, W.-J. Angew. Chem., Int. Ed. 2015, 54, 11196-11199. doi:10.1002/anie.201504559

25. Jia, K.; Zhang, F.; Huang, H.; Chen, Y. J. Am. Chem. Soc. 2016, 138, 1514-1517. doi:10.1021/jacs.5b13066

26. Jia, K.; Pan, Y.; Chen, Y. Angew. Chem., Int. Ed. 2017, 56, 2478-2481. doi:10.1002/anie.201611897

27. Jia, K.; Li, J.; Chen, Y. Chem. - Eur. J. 2018, 24, 3174-3177. doi:10.1002/chem.201800202

28. Togo, H.; Taguchi, R.; Yamaguchi, K.; Yokoyama, M. J. Chem. Soc., Perkin Trans. 1 1995, 2135-2139. doi:10.1039/p19950002135

29. Brand, J. P.; Chevalley, C.; Scopelliti, R.; Waser, J. Chem. - Eur. J. 2012, 18, 5655-5666. doi:10.1002/chem.201200200

30. Fernández González, D.; Brand, J. P.; Mondière, R.; Waser, J. Adv. Synth. Catal. 2013, 355, 1631-1639. doi:10.1002/adsc.201300266

31. Lu, B.; Wu, J.; Yoshikai, N. J. Am. Chem. Soc. 2014, 136, 11598-11601. doi:10.1021/ja5059795

32. Hari, D. P.; Waser, J. J. Am. Chem. Soc. 2017, 139, 8420-8423. doi:10.1021/jacs.7b04756

33. While not all the substituted o-iodobenzoic acids are commercially available, the substituted $o$-aminobenzoic acids are readily available in reasonable price and can synthesize the corresponding substituted o-iodobenzoic acids by Sandmeyer reaction in one step in $85-90 \%$ yields.

34. Li, G.-X.; Morales-Rivera, C. A.; Wang, Y.; Gao, F.; He, G.; Liu, P.; Chen, G. Chem. Sci. 2016, 7, 6407-6412. doi:10.1039/C6SC02653B 


\section{License and Terms}

This is an Open Access article under the terms of the Creative Commons Attribution License

(http://creativecommons.org/licenses/by/4.0), which permits unrestricted use, distribution, and reproduction in any medium, provided the original work is properly cited.

The license is subject to the Beilstein Journal of Organic Chemistry terms and conditions:

(https://www.beilstein-journals.org/bjoc)

The definitive version of this article is the electronic one which can be found at:

doi:10.3762/bjoc. 14.103 